\title{
A JUDICIALIZAÇÃO DA SAÚDE NO BRASIL E A REGULAÇÃO DA SAÚDE SUPLEMENTAR ATRAVÉS DA AGÊNCIA NACIONAL DE SAÚDE.
}

\author{
Simone Letícia Severo e Sousa Dabés Leão ${ }^{1}$ \\ Sabrina Nunes Borges ${ }^{2}$
}

RESUMO: O setor de saúde no Brasil é formado por um sistema público, financiado pelo Estado por intermédio do SUS e por um sistema privado, denominado de saúde suplementar. No que tange à saúde suplementar, o Estado passou a atuar como regulador dos mercados, por intermédio da ANS. Evidencia-se que a Judicialização da Saúde, traz uma preocupação não só aos gestores do SUS, bem como aos gestores privados e operadores do Direito, especialmente no tocante à necessidade de critérios para pautar as decisões. O escopo é apresentar reflexões acerca da regulação da saúde suplementar. $\mathrm{O}$ trabalho explora metodologia qualitativa, do tipo exploratória, por coleta de dados, com revisão bibliográfica.

Palavras-chave: Regulação. Saúde Suplementar. ANS. Judicialização da Saúde. Jurisprudência.

\section{THE JUDICIALIZATION OF HEALTH IN BRAZIL AND THE REGULATION OF THE SUPPLEMENTAL HEALTH SYSTEM THROUGH THE NATIONAL REGULATORY AGENCY FOR PRIVATE HEALTH.}

\begin{abstract}
Brazilian's health sector is composed of a public system, financed by the Government through the Unified Health System (SUS), as well as by a private system, entitled as supplemental health system. With regard to the mentioned supplemental health system, the Government started to intervene and act as a market regulator, through the National Regulatory Agency for Private Health (ANS). The judicialization of health is a matter of concern not only to the Unified Health Service (SUS) managers, but also to private managers and legal practitioners, especially in relation to the establishment of decisionmaking criteria. This article aims to present reflections concerning the regulation of the supplemental health system; through an exploratory and qualitative methodology, data collection and bibliographic review.
\end{abstract}

Key words: Regulation. Supplemental Health. National Regulatory Agency for Private Health. ANS. Judicialization of health. Jurisprudence.

\footnotetext{
Pós-Doutora em Direitos Humanos pela Universidade Salamanca. Doutora em Direito Público (PUCMinas/Belo Horizonte). Mestre em Direito das relações econômico-empresariais (Unifran/São Paulo). Professora Universitária. Membro do Comitê Mineiro de Saúde - COGESMIG. Assessora Judiciária - TJMG.

${ }^{2}$ Doutoranda em Processo Coletivo e Proteção dos Direitos Fundamentais pela Universidade de Itaúna. Mestre em Processo Coletivo e Proteção dos Direitos Fundamentais pela Universidade de Itaúna. Especialista em Direito Público. Professora Universitária. Advogada.
} 


\section{INTRODUÇÃO}

A assistência à saúde no Brasil configura um direito social, assegurado pelo art. $6^{\circ}$ da Constituição Federal.

A Constituição da República de 1988, em seu art. 196, determinou que a saúde é um direito de todos, motivo pelo qual o Sistema Único de Saúde (SUS) deve atender toda e qualquer pessoa, indistintamente.

Ver-se-á que o Sistema de Saúde Brasileiro é composto principalmente por serviços privados e constitui-se num dos maiores mercados de compra e venda de serviços de saúde do mundo. Tanto que a própria Constituição autorizou a atuação da iniciativa privada na prestação de serviços de assistência à saúde.

Se por um lado a assistência à saúde é um dever do Estado, por outro, o Poder Público admite que as ações e serviços de saúde sejam prestados pela iniciativa privada. É o que se depreende do art. 199, “caput”, segundo o qual a assistência á saúde é livre à iniciativa privada.

Desse modo, ao mesmo tempo em que o Estado possui o dever de garantir saúde à população, o que o faz pelo Sistema Único de Saúde, a Constituição Federal reconhece à iniciativa privada a liberdade de desenvolver ações e serviços privados de saúde.

Embora a Saúde Suplementar tenha surgido no Brasil na década de 1960, só foi regulamentada no final da década de 1990, através da Lei n. 9.656 de 1998.

A Agência Nacional de Saúde Suplementar - ANS foi criada no ano de 2000, pela Lei n. 9.961 de 2000 .

A saúde suplementar, não faz parte do SUS (Sistema Único de Saúde). Já a Saúde complementar, faz parte do SUS e está prevista no artigo 199, § $1^{\circ}$ da Constituição da República, que reza que as instituições privadas poderão participar de forma complementar do SUS. Diz-se complementar porque essa participação das entidades privadas no SUS só ocorrerá quando o sistema público não possuir meios para suprir as necessidades da população. É por meio dessa previsão constitucional que o setor privado, destaque para o lucrativo, está autorizado a complementar as ações e serviços de saúde que fazem parte do SUS, que é a rede de ações e serviços públicos de saúde prevista no artigo 198 da Constituição da República. Quando atuam de forma complementar no SUS, as empresas privadas, dentre elas as com fins lucrativos, devem submeter-se ao princípios e diretrizes 
desse Sistema de Saúde e devem ser contratadas por meio de contrato de direito público (199, $\S 1^{\circ}$ ), o que não ocorre com as empresas privadas do setor saúde suplementar.

As relações entre o público e o privado, na saúde, exigem a ampliação dos debates, a fim de que a regulação do mercado venha a orientar-se para a melhoria das condições de saúde. Ademais, a saúde dá lucro quando é particular e não quando é pública. O pior é quando há tamanha destruição da saúde pública para favorecer a saúde privada. Muitos querem impor a lógica do lucro na saúde pública. A privatização da saúde faz com que a qualidade dos serviços caia e os custos aumentam.

A ideia da iniciativa privada é consequentemente o lucro a todo custo. Já, se o hospital é público, deve ter um controle social efetivo e não buscar o lucro e sim o bem da coletividade.

Ver-se-á que a Agência Nacional de Saúde assume grande relevância no sistema nacional de saúde, atuando de forma complementar no Sistema Único de Saúde.

Questiona-se se a agência reguladora (ANS) conseguirá promover, de forma adequada e efetiva, a assistência suplementar à saúde, regulando as operadoras do setor, bem como suas relações com os consumidores.

A pesquisa pautar-se-á na análise do problema, visando principalmente discutir e analisar a efetividade da saúde suplementar no Brasil, através da Agência Nacional de Saúde, com análise de casos concretos das Cortes Superiores Brasileiras atinentes à Judicialização da Saúde Suplementar.

Será realizada pesquisa precipuamente qualitativa, do tipo exploratória, por coleta de dados, fazendo uso de instrumentos de coleta de dados de pesquisa bibliográfica e documental.

\section{A EVOLUÇÃO, FUNÇÃO E CARACTERÍSTICAS DO PROCESSO DE REGULAÇÃO DA SAÚDE SUPLEMENTAR.}

As agências reguladoras no Brasil foram criadas por Lei a partir de meados dos anos 90 (Século XX). As agências concebidas como agentes do Estado têm autonomia em relação aos governos, tendo como suas características principais são a independência administrativa e financeira e a sua autonomia decisória para implementar políticas do Executivo e do 
Legislativo. A criação das agências faz parte de uma mudança na redefinição do papel do Estado, da sua gerência, de suas responsabilidades e da sua relação com a economia.

A política regulatória de planos de saúde se resume, no âmbito da Reforma do Estado, aos princípios da não interferência do Estado nos assuntos do mercado e ao estabelecimento das garantias necessárias para seu funcionamento. Estas se resumem a três princípios básicos: a) evitar a captura dos reguladores pelo regulado, b) garantir a competitividade no mercado, c) evitar monopólios que inviabilizem o próprio mercado. A legislação regulatória se debate, a partir desse momento e, mais especificamente, a partir do governo eleito em 2002, entre os princípios da Reforma do Estado e os princípios da Reforma Sanitária promulgada pela Constituição Cidadã de 1988... Os aspectos relativos à regulação do setor estatal sobre o privado têm avançado no contexto da Reforma do Estado que criou as agências regulatórias. No caso da saúde, a ANS, cujas atribuições relativas a mecanismos de operacionalização de dispositivos jurídicos não outorgam poderes suficientes à Agência sobre os agentes regulados, como se pode observar no caso da Resolução Normativa relativa ao ressarcimento das operadoras ao SUS pela utilização privada de serviços públicos. (GERSCHMAN, 2008, p. 2).

O setor de saúde no Brasil é formado por um sistema público, financiado pelo Estado por intermédio do Sistema Único de Saúde (SUS), e por um sistema privado, denominado de saúde suplementar, cujos financiadores são as operadoras de planos de assistência médica.

Desse modo, paralelamente à saúde pública, tem-se ainda, a assistência privada à saúde, também chamada de saúde suplementar, objeto de contrato de direito privado, celebrado entre as operadoras de planos de saúde e o consumidor.

O termo regulação tem sido utilizado no âmbito da saúde com um sentido mais amplo do que a mera regulamentação dos mercados, estando relacionado a uma função desempenhada pelos sistemas de saúde em geral, mesmo nos majoritariamente públicos, não sendo apenas uma função de regulação mais clássica das relações de mercado na saúde, como uma das maneiras de correção das chamadas imperfeições de mercado. Pela diversidade dos sistemas de saúde e abrangência da função de Estado na saúde, o termo assume claramente uma característica polissêmica. (MAGALHÃES JR. 2006, p. 40).

Na prática, nota-se que a ANS exerce o papel mais regulamentando do que regulando o setor de saúde suplementar. 
No novo modelo de organização do Estado buscou-se a redução da atuação estatal, criaram-se entes autônomos que receberam o nome de agências reguladoras ${ }^{3}$.

Carlos Ari Sundfeld assevera que compete às agências reguladoras:

Regular certas atividades desempenhadas por particulares, produzir normas jurídicas gerais e abstratas sobre o desenvolvimento dessas atividades, atribuir ou suprimir aos particulares o direito de desempenhar essas atividades, é dizer, dar-lhes autorizações, concessões, permissões, licenças, ou outras formas de atos pelos quais os particulares são habilitados a desempenhar as atividades, serviços públicos ou não. (SUNDFELD, 1998, p. 134).

Há que diferenciar agência reguladora de agência executiva, principalmente uma vez que a agência executiva configura a qualificação dada à autarquia, fundação pública ou órgão da administração direta que celebre contrato de gestão com o próprio ente político com o qual está vinculado.

Maria Sylvia Zanella de Pietro, ao tratar da agência executiva salienta que em regra, não se trata de entidade instituída com a denominação de agência executiva. Trata-se de entidade preexistente (autarquia ou fundação governamental) que, uma vez preenchidos os requisitos legais, recebe a qualificação de agência executiva, podendo perdê-la se deixar de atender os mesmos requisitos. (DI PIETRO, 2003, p. 366).

As primeiras experiências das agências reguladoras foram do Banco Central e do CADE, porém com o processo de desestatização, envolvendo privatizações e concessões, o papel das agências tornou-se relevante, como no caso da saúde, do petróleo e do setor de telecomunicações.

A ANS (Agência Nacional de Saúde Suplementar) difere das outras agências, pois nesse setor não houve privatização de entidades estatais que prestavam serviços e não existia qualquer tipo de intervenção estatal na atividade econômica específica até 1998, com o advento da Lei n. 9.656/98, que passou a dispor sobre a prestação de serviço e o funcionamento das operadoras de planos privados de assistência à saúde. (GREGORI, 2010, p. 65).

\footnotetext{
${ }^{3}$ Alexandre Santos Aragão adota o conceito da moderna regulação (2004, p. 144): A regulação estatal da economia é o conjunto de medidas legislativas, administrativas e convencionais, abstratas e concretas, pelas quais o Estado, de maneira restritiva da liberdade privada ou indutiva, determina, controla ou influencia o comportamento dos agentes econômicos, evitando que lesem os interesses sociais definidos no marco da constituição e orientando-os em direções socialmente desejáveis. Santos, por sua vez, salienta (2008, p. 1463): A regulação assistencial foi uma inovação no período e se revelou apropriada no sentido da indução de novas práticas assistenciais, valorizando a promoção e prevenção, bem como a introdução de mecanismos de avaliação de qualidade (projeto de qualificação).
}

Rev. de Direito Sociais e Políticas Públicas | e-ISSN: 2525-9881 | Evento Virtual | v. 6 | n. 1 | 
A Lei n. 9.961/2000 criou a Agência Nacional de Saúde Suplementar - ANS e definiu a sua finalidade, estrutura, atribuições, receita, natureza e vinculação ao Ministério da Saúde. A regulação exercida pela agência possui papel fundamental no cumprimento das políticas determinadas pelo Estado e sua função legal é gerencial (técnica), de controle e fiscalização sobre os entes regulados no setor de Saúde Suplementar. ${ }^{4}$

Evidencia-se, pois, que a regulação no setor da saúde ocorre para "proteger" os cidadãos/consumidores das falhas existentes no mercado. Assim, a regulação visa corrigir ineficiências do mercado, estabelecendo regras entre consumidores e empresas/operadoras de planos de saúde.

Para Gama:

Até 1994, as operadoras viviam num "paraíso". Este paraíso sofreu inúmeras modificações a partir da publicação de vários dispositivos legais, em especial a Lei n. 9656-98, a qual veio a regulamentar o setor. Após a regulação, tornou-se obrigatória a assistência integral à saúde, foi proibida a rescisão unilateral dos contratos e os ajustes de preço passaram a ser controlados por um órgão regulador. (GAMA, 2006, p. 15).

Trata-se aqui da chamada privatização da saúde, afinal a saúde é serviço público. E quanto à privatização da saúde basta observar o incentivo que o cidadão tem em seu Imposto de renda, quando utiliza serviços de saúde particulares, seja através de planos de saúde ou não.

Frise-se, que a saúde é um dever do Estado e em regra deve ser prestada por ele, e apenas, excepcionalmente, pela iniciativa privada.

\footnotetext{
${ }^{4}$ Nos termos do art. $4^{\circ}$ Lei n. 9.961 de 2000, compete à ANS: I - propor políticas e diretrizes gerais ao Conselho Nacional de Saúde Suplementar - Consu para a regulação do setor de saúde suplementar; II - estabelecer as características gerais dos instrumentos contratuais utilizados na atividade das operadoras; III - elaborar o rol de procedimentos e eventos em saúde, que constituirão referência básica para os fins do disposto na Lei $\mathrm{n}^{\circ} 9.656$, de 3 de junho de 1998, e suas excepcionalidades; IV - fixar critérios para os procedimentos de credenciamento e descredenciamento de prestadores de serviço às operadoras; V - estabelecer parâmetros e indicadores de qualidade e de cobertura em assistência à saúde para os serviços próprios e de terceiros oferecidos pelas operadoras; VI - estabelecer normas para ressarcimento ao Sistema Único de Saúde - SUS; VII - estabelecer normas relativas à adoção e utilização, pelas operadoras de planos de assistência à saúde, de mecanismos de regulação do uso dos serviços de saúde;

VIII a XLI - omissis. ... XLII - estipular índices e demais condições técnicas sobre investimentos e outras relações patrimoniais a serem observadas pelas operadoras de planos de assistência à saúde.
} 
No plano da oferta, o sistema de saúde brasileiro é composto, principalmente, por serviços privados. E constitui-se num dos maiores mercados de compra e venda de serviços de saúde no mundo. Essa realidade forçou a separação, no país do financiamento e da provisão desses serviços antes mesmo que essa recomendação fosse incluída na de reformas do sistema sanitário. Esse grande mercado privado, - profissionais, médicos, ambulatórios, hospitais, serviços diagnóstico-terapêuticos, laboratórios - vende serviços de saúde tanto para o setor público como para os planos e seguros privados. (BRASIL, 2002, p. 7-8).

A regulação pode ser entendida num processo evolutivo da atuação do Estado na economia, como uma função administrativa, que não decorre necessariamente do poder político, e sim da abertura pela lei, de um espaço decisório sobre conflitos de interesses concorrentes dentro da sociedade.

A função da regulação é entendida como estratégia em estreita interface com o planejamento, o controle, a avaliação e com os diversos níveis de complexidade da assistência, buscando garantir a assistência integral aos usuários do SUS. A regulação é um dos instrumentos de gestão que viabiliza o ordenamento da relação dos usuários com os prestadores de saúde.

Note-se que a função da regulação possui estreita relação com o planejamento, o controle, a avaliação e com os diversos níveis de complexidade da assistência, buscando garantir a assistência integral aos usuários do SUS.

\section{A ANS E A REGULAÇÃO DA SAÚDE SUPLEMENTAR NO BRASIL.}

A ANS possui natureza de autarquia sob regime especial, vinculada ao Ministério da Saúde, com sede e foro na cidade do Rio de Janeiro, prazo de duração indeterminado e atuação em todo o território nacional. De forma simplificada, pode-se afirmar que a ANS possui natureza de órgão de regulação, normatização, controle e fiscalização das atividades que garantam a assistência suplementar à saúde. (MARTINS, 2008, p. 198-199).

Maria Stella Gregori ainda assevera:

Assim como as demais agências, a ANS goza de autonomia administrativa e financeira e tem orçamento próprio composto, como principal fonte de receita, pela Taxa de saúde Suplementar - TSS, além de multas (administrativa e de mora). Sua diretoria é composta por cinco diretores, sendo um diretor-presidente, com mandatos de três anos... A ANS tem como escopo regular o sistema privado de saúde 
disciplinando e controlando as atividades que garantam a assistência suplementar. Ela não regula todos os serviços de saúde, tais como prestadores de serviços, médicos, hospitais, medicamentos, mas apenas as operadoras de planos de assistência à saúde. A ANS é um autarquia, sob regime de natureza especial, vinculada ao Ministério da saúde, subordinada às diretrizes fixadas pelo Consu. Sua atuação é controlada pelo contrato de gestão, firmado pelo Ministério da saúde e aprovado pelo Consu. (GREGORI, 2010, p. 64-70).

A Lei n. 9.656/98 tem por objetivo regular as operadoras de planos de assistência à saúde e os próprios planos, cabendo à ANS regular e fiscalizar a atuação das operadoras em geral.

Com a Lei n. 9.656/98 passou-se a ter dois tipos de contratos: o contrato regulamentado (contrato novo) e o não regulamentado (contrato antigo). O contrato não regulamentado seria o contrato anterior à Lei n. 9.656/98 em que a cobertura estaria adstrita a um determinado contrato assinado entre a operadora de planos de saúde e o beneficiário.

A ANS, criada pela Lei n. 9.961, de 28/01/2000 ${ }^{5}$, tem como objetivo precípuo a regulação, a normatização, o controle e a físcalização das atividades que garantam a manutenção e a qualidade dos serviços privados de atenção médico-hospitalar ou odontológica prestados por intermédio da operação de planos de saúde. Além disso, também lhe compete a defesa de interesse público na assistência suplementar à saúde, regulando as operadoras setoriais, inclusive quanto às suas relações com prestadores consumidores, contribuindo para o desenvolvimento das ações de saúde no país. (GREGORI, 2010, p. 64).

A ANS é dirigida por uma Diretoria Colegiada e conta com unidades especializadas incumbidas de diferentes funções, de acordo com seu regimento interno. A Diretoria Colegiada é composta por até cinco Diretores, sendo um deles seu Diretor-Presidente, tendo todos mandatos de 3 anos não coincidentes ${ }^{6}$ (CRUZ, 2004, p. 37). As cinco diretorias são: Diretorias de fiscalização (DIFIS), de desenvolvimento setorial (DIDES), de normas e habilitação de produtos (DIPRO) e de normas e habilitação de operadoras (DIOPE), bem como a Diretoria de Gestão (DIGES). ${ }^{7}$

\footnotetext{
${ }^{5}$ De acordo com o artigo $3^{\circ}$ da lei $9.961 / 2000$ : a ANS terá por finalidade institucional promover a defesa do interesse público na assistência suplementar da saúde, regulando as operadoras setoriais, inclusive quanto suas relações com prestadores consumidores, contribuindo para o desenvolvimento das ações de saúde no país.

${ }^{6}$ De acordo com o art. 6 da Lei n. 9.961 de 2000: A gestão da ANS será exercida pela Diretoria Colegiada, composta por até cinco Diretores, sendo um deles seu Diretor-Presidente.

${ }^{7}$ A ANS está organizada em cinco áreas:
}

Rev. de Direito Sociais e Políticas Públicas | e-ISSN: 2525-9881 | Evento Virtual | v. 6 | n. 1 | 
A Lei n. $9.656 / 98^{8}$ delineia a regulação sobre três aspectos principais: a) o institucional, com a fixação de regras de entrada, permanência e saída das operadoras no mercado de saúde suplementar; b) o econômico-financeiro, ao estabelecer normas relativas à solvência e liquidez das operadoras; c) e o assistencial, mediante o disciplinamento da cobertura assistencial, abrangência dos planos, rede credenciada, procedimentos e eventos cobertos e não cobertos, carências, reajustes, doenças e lesões preexistentes e cumprimento de cláusulas contratuais. (GREGORI, 2010, p. 144).

Em seu art. $1^{\circ}$, a Lei aponta a quem ela se dirige, mostrando os sujeitos e o objeto do mercado de saúde suplementar:

Submetem-se às disposições desta Lei as pessoas jurídicas de direito privado que operam planos de assistência de saúde, sem prejuízo do cumprimento da legislação específica que rege a sua atividade, adotando-se, para fins de aplicação das normas aqui estabelecidas, as seguintes definições...

Cabe à ANS a aplicação das penalidades pelo descumprimento da Lei n. 9.656/98, bem como sua regulamentação. A Lei n. 9.656/98, em seu art. $1^{\circ}$, inciso I define plano privado de assistência à saúde como:

Prestação continuada de serviços ou cobertura de custos assistenciais a preço pré ou pós estabelecido, por prazo indeterminado, com a finalidade de garantir, sem limite financeiro, a assistência à saúde, pela faculdade de acesso e atendimento por profissionais ou serviços de saúde, livremente escolhidos, integrantes ou não de rede credenciada, contratada ou referenciada, visando a assistência médica, hospitalar e odontológica, a ser paga integral ou parcialmente às expensas da operadora contratada, mediante reembolso ou pagamento direto ao prestador, por conta e ordem do consumidor.

- Diretoria de Normas e Habilitação das operadoras: responsável pela regulamentação, registro e monitoramento do funcionamento das operadoras, inclusive dos processos de regime especial e liquidação extrajudicial;

- Diretoria de Normas e Habilitação de produtos: responsável pela regulamentação, registro e monitoramento dos planos, inclusive as autorizações de reajustes de contratos;

- Diretoria de Fiscalização: responsável por todo o processo de fiscalização tanto dos aspectos econômico-financeiros, quanto dos aspectos médico-assistenciais, além do apoio ao consumidor e articulação com os órgãos de defesa do consumidor;

- $\quad$ Diretoria de desenvolvimento Setorial: responsável pela integração com o SUS e sistemas de informações em saúde suplementar; e

- Diretoria de Gestão: responsável pelo desenvolvimento e integração institucional.

${ }^{8}$ Ressalte-se que com a MP 2.177-44 de 24.08.2001, a Lei 9.656-98 sofreu inúmeras modificações. 
De acordo com o artigo $1^{\circ}$ da Resolução n. 39, de 27/10/2000, da Agência de Saúde Suplementar:

Definem-se como Operadoras de Assistência à Saúde as empresas e entidades que operam no mercado de saúde suplementar, planos de assistência à saúde, conforme disposto na Lei 9.656/98.

Parágrafo único: Para efeito dessa Resolução, define-se operar como sendo as atividades de administração, comercialização ou disponibilização dos planos de que trata o caput deste artigo.

Criou-se o Sistema de Informações de Produtos (SIP), que obriga as operadoras a fornecer dados sobre exames, consultas, internações, partos e demais despesas por usuários, bem como informações sobre o monitoramento gerencial e assistencial. Criou-se também a Troca de informações em Saúde Suplementar (TISS), que visa estabelecer um padrão obrigatório para as informações trocadas entre as operadoras e prestadores de serviços, visando a melhoria do atendimento dos consumidores de planos privados de assistência à saúde.

Os Núcleos da ANS passam a ter a atribuição de fiscalizar, em suas áreas de atuação, as operadoras médico-hospitalares líderes de mercado. O Programa Olho Vivo irá analisar questões econômico-financeiras e aspectos assistenciais e as operadoras fiscalizadas pela sede não serão objeto da fiscalização dos Núcleos.

Cabe também à ANS celebrar, nas condições que estabelecer, Termo de Compromisso de Ajuste de Conduta e Termo de Compromisso, fiscalizando o seu cumprimento. O Termo de Compromisso de Ajuste de Conduta constitui o procedimento cabível após a lavratura do auto de infração. O Termo de Ajuste de Conduta constitui regra geral para as condutas relacionadas a obrigações de natureza regulatória e decorrentes da ação fiscalizatória pró-ativa da ANS (Programa Olho Vivo) e da ação de monitoramento (Representações). O TCAC constitui o acordo celebrado entre a ANS e as operadoras, pelo qual elas se comprometem a cessar a prática irregular e a corrigir eventuais danos causados, Já o TC - é o acordo com operadoras, quando houver interesse de que sejam implementadas práticas que se transformem em vantagens para os consumidores. O TC pode implicar restrições de direitos do consumidor ${ }^{910}$.

\footnotetext{
${ }^{9}$ Disponível <http://www.ans.gob.br.html> Acesso em 26 mar. 2013. Para autora: o resultado esperado, depois de implantado esses dois Programas, é fazer com que as ações de fiscalização não se restrinjam apenas ao seu
} 
Já a fiscalização indireta da ANS é exercida através do acompanhamento e monitoramento das operadoras, com base nos dados fornecidos nos sistemas de informações periódicas e no cruzamento das informações disponíveis, bem como nas reclamações e nas multas aplicadas.

Saliente-se que, existe também, desde 2001, o Disque-ANS, um serviço nacional gratuito, que recebe atendimentos telefônicos sobre consultas e denúncias.

A partir de 2006, houve uma mudança significativa no enfoque da fiscalização, com o intuito de se criar uma mediação ativa para os conflitos, através da reparação voluntária e eficaz e da criação da NIP (Notificação de Investigação Preliminar). O Procedimento NIP trata de uma notificação às operadoras de planos de saúde acerca das demandas recebidas antes da abertura de processo administrativo. Tal procedimento permite ao órgão regulador atuar na solução dos conflitos, uma vez que há a reparação voluntária e eficaz por parte da operadora.

Reza o art. $3^{\circ}$ da Lei n. 9.656/98 que, a ANS tem por finalidade institucional promover a defesa do interesse público na assistência suplementar à saúde, regulando as operadoras setoriais, inclusive quanto às suas relações com prestadores e consumidores, contribuindo para o desenvolvimento das ações de saúde no país.

A regulamentação, aprovada em junho de 1998, entrou em vigor efetivamente a partir de janeiro de 1999 e neste intervalo são editadas várias resoluções do Conselho de Saúde Suplementar (CONSU) ${ }^{11}$, necessárias para viabilizar as exigências da legislação federal.

Em junho de 2018, a ANS editou Resolução autorizando as operadoras a reajustarem os planos de saúde individuais e familiares, tomando por base a média de reajustes de planos

aspecto punitivo, mas se proteje, também, como instrumento de importante transformação na atitude dos agentes desse mercado e contribua para estabelecer um novo padrão de conduta para as operadoras tanto no que diz respeito a uma maior aderência às normas, quanto às práticas que respeitem o consumidor.

${ }^{10}$ Previsão Legal no Âmbito da Saúde Suplementar: Artigo 29 e seus parágrafos da Lei $\mathrm{n}^{\circ}$ 9.656/98. Artigo $4^{\circ}$, inciso XXXIX, da Lei $n^{\circ}$ 9.961/2000 . Regulamentação pela ANS: RDC n ${ }^{\circ}$ 57, de 19 de fevereiro de 2001. E ainda: Art. $1^{\circ}$ A ANS poderá firmar com as operadoras dos produtos de que trata o inciso I e $\S 1^{\circ}$ do art. $1^{\circ}$ da Lei n. ${ }^{\circ}$ 9656, de 1998, termo de compromisso de ajuste de conduta, na forma desta resolução, com vistas a adequar sua conduta à legislação pertinente e às diretrizes gerais estabelecidas para o setor de saúde suplementar. (RDC n. ${ }^{\circ}$ 57/01) (Grifou-se)

${ }^{11}$ O Conselho de Saúde Suplementar (CONSU) é órgão integrante da estrutura regimental do Ministério da saúde, composto por Ministro de Estados, com a competência para supervisionar a execução de políticas de saúde, aprovar o contrato de gestão da ANS e fixar normas para constituição, organização, funcionamento e fiscalização das empresas operadoras. (MARTINS, 2008, p.198) Portanto, esse Conselho é formado pelos Ministros da saúde, da Fazenda, do Planejamento, Orçamento e Gestão, sendo presidido pelo Ministro da Justiça, tendo como atribuição fixar as políticas públicas a serem executadas pela ANS. 
coletivos, em até $10 \%$, índice muito superior aos 5,72\% de inflação para o seguimento de saúde e cuidados pessoais acumulada em 12 meses até maio daquele ano. Os planos coletivos não estão sujeitos a controle de preços, o que coloca como ainda mais problemática a situação de seus beneficiários. (SANTOS, 2018)

Posteriormente, a Agência Nacional de Saúde Suplementar (ANS) divulgou na data de 23/07/2019 o percentual máximo de reajuste que poderá ser aplicado nas mensalidades dos planos de saúde individuais ou familiares com aniversário no período de maio de 2019 a abril de 2020. O índice foi estabelecido em $7,35 \% .^{12}$

De acordo com a ANS, no ano de 2019, o Brasil atingiu o número de 47.039.728 de beneficiários de planos de saúde por cobertura assistencial. ${ }^{13}$

\section{A JUDICIALIZAÇÃO DA SAÚDE SUPLEMENTAR.}

O gasto privado em saúde, no Brasil, revela uma distorção: apesar de contar com o maior sistema de saúde pública universal do mundo, a participação da despesa privada com saúde, incluindo seguros-saúde, é comparável à de países nos quais a assistência à saúde é um negócio essencialmente privado, como nos EUA, onde inexiste um sistema público universal. (SANTOS, 2018).

A questão é bastante preocupante, principalmente tendo em vista o número assustadoramente crescente das demandas judiciais em que os cidadãos pleiteiam o acesso à saúde.

Diante disso, observa-se que a alternativa para coibir as omissões e-ou falhas, seja dos entes federados, seja das operadoras de planos de saúde, é através da chamada Judicialização da Saúde.

O fato do tratamento médico indicado não constar no rol da ANS tem gerado inúmeras demandas judiciais, uma vez que os tribunais têm entendido que o rol da agência reguladora é meramente exemplificativo.

\footnotetext{
${ }^{12}$ De acordo com a ANS, o reajuste é válido para os planos de saúde individuais ou familiares médicohospitalares contratados a partir de janeiro de 1999 ou adaptados à Lei ${ }^{\circ}$ 9.656/98. Atualmente, compreende cerca de $17 \%$ do total de beneficiários em planos de assistência médica, ou seja, aproximadamente 8 milhões de usuários, de acordo com dados referentes a maio de 2019. Disponível em http://www.ans.gov.br/aans/noticias Acesso em 07 de março de 2020.

${ }^{13}$ Sistema de Informações de Beneficiários SIB-ANS (dados atualizados até dezembro de 2019).
} 
Nesse sentido:

EMENTA: AGRAVO DE INSTRUMENTO - AÇÃO DE OBRIGAÇÃO DE FAZER - PLANO DE SAÚDE - CÓDIGO DE DEFESA DO CONSUMIDOR APLICAÇÃO - TUTELA DE URGÊNCIA ANTECIPATÓRIA - REQUISITOS PRESENÇA - TRATAMENTO DE SAÚDE - INDICAÇÃO DO MÉDICO RECUSA DE COBERTURA - NÃO CABIMENTO - ROL DA ANS - CARÁTER EXEMPLIFICATIVO.

1- Nos termos da Súmula n 469 do STJ: "Aplica-se o Código de Defesa do Consumidor aos contratos de plano de saúde". 2- A possibilidade de concessão da tutela de urgência em caráter antecedente, disciplinada nos artigos 300 e 303 do Código de Processo Civil, deve ser analisada mediante a verificação concomitante dos requisitos da probabilidade do direito invocado e do perigo de dano ou risco ao resultado útil do processo.3- O profissional de saúde que acompanha o paciente é o mais indicado para prescrever o correto tratamento, levando-se em consideração as particularidades específicas de cada caso concreto.

4- É entendimento sedimentado no Superior Tribunal de Justiça ser de caráter exemplificativo o rol de procedimentos mínimos obrigatórios elaborado pela Agência Nacional de Saúde Suplementar - ANS, não sendo cabível a negativa de cobertura de procedimento indicado pelo médico para tratar doença prevista no contrato com base na inexistência de previsão expressa do método no citado rol. (TJMG - Agravo de Instrumento-Cv 1.0000.19.124981-2/001, Relator(a): Des.(a) Claret de Moraes, $10^{a}$ CÂMARA CÍVEL, julgamento em 28/01/2020, publicação da súmula em 04/02/2020)

De acordo com o entendimento do Relator Des. Claret de Moraes, comprovada a necessidade da realização do referido exame, é dever da operadora de plano de saúde custeálo, somando-se ao fato de haver notícia de que o tratamento com o fármaco indicado pelo médico já apresentou resultados significativos.

No mesmo sentido, destacou o Relator Des. Amorim Siqueira, salientando que ao contratar um plano de saúde o consumidor espera ter a garantia da prestação de serviços médicos e hospitalares em caso de necessidade, estando incluso não apenas a realização de consultas, mas também as cirurgias, materiais e tratamentos necessários à manutenção de sua vida:

APELAÇÃO CÍVEL - AÇÃO DE OBRIGAÇÃO DE FAZER - PLANO DE SAÚDE - RECUSA DE COBERTURA - PROCEDIMENTO QUIMIOTERÁPICO OCULAR - CÓDIGO DE DEFESA DO CONSUMIDOR - APLICABILIDADE CLÁUSULA RESTRITIVA ABUSIVA - COBERTURA DEVIDA - RECURSO PROVIDO.

- A interpretação das cláusulas contratuais deve ser feita à luz da legislação consumerista, de modo a relativizar a exclusão da cobertura do tratamento em benefício do restabelecimento da saúde do paciente. - A Agência Nacional de Saúde (ANS) define um rol de consultas, exames e tratamentos, que os planos de saúde são obrigados a oferecer. Cuida-se, na verdade, de uma listagem que contém o mínimo 
de procedimentos que as operadoras de saúde suplementares são obrigadas a oferecer, não constituindo, por conseguinte, um rol taxativo. - Comprovado que a ausência do tratamento indicado implicará na progressão da doença com perda importante da capacidade visual do contratante, impõe-se à operadora arcar com os custos do recurso terapêutico prescrito. (TJMG - Apelação Cível 1.0000.18.069340-0/002, Relator(a): Des.(a) Amorim Siqueira , 9 ${ }^{\mathrm{a}}$ CÂMARA CÍVEL, julgamento em 04/06/2019, publicação da súmula em 18/06/2019) (grifouse)

A Resolução Normativa $n^{\circ}$ 211, Anexo II, da ANS, transforma em obrigatória a cobertura do procedimento de cirurgia bariátrica pela saúde suplementar, mesmo tal procedimento cirúrgico não constando do rol dos serviços médicos não cobertos pelo plano de saúde:

EMENTA: APELAÇÃO - OBRIGAÇÃO DE FAZER - COBERTURA À CIRURGIA BARIÁTRICA - OBESIDADE MÓRBIDA - AUSÊNCIA DE EXCLUSÃO EXPRESSA NO CONTRATO CELEBRADO COM O PLANO DE SAÚDE - PREVISÃO NA ANS COMO PROCEDIMENTO OBRIGATÓRIO NEGAR PROVIMENTO AO RECURSO. Está demonstrada a necessidade da realização da cirurgia bariátrica em paciente com 44 anos, portadora de obesidade crônica grau II com IMC igual a 36,5, associada à hipertensão arterial e pré-diabetes, restando frustrados outros tratamentos clínicos para a redução do peso. Neste caso, segundo a ANS - Agência Nacional de Saúde, em sua Resolução Normativa no 211, Anexo II, transforma em obrigatória a cobertura do procedimento de cirurgia bariátrica pela saúde suplementar. E a cirurgia ora pleiteada não constou do rol dos serviços médicos não cobertos pelo plano de saúde. (TJMG - Apelação Cível 1.0223.12.006913-1/003, Relator(a): Des.(a) Mota e Silva , $18^{\mathrm{a}}$ CÂMARA CÍVEL, julgamento em 07/05/2019, publicação da súmula em 10/05/2019)

Para o Relator Des. Mota e Silva, a previsão da ANS deve ser compreendida apenas como um panorama de cobertura mínima a ser observada pelos planos privados de assistência à saúde, devendo se atentar que o mero fato de o procedimento não integrar o rol da ANS possui aspecto secundário.

Desse modo, evidencia-se que o rol de procedimentos da Agência Nacional de Saúde Suplementar (ANS) serve de mera referência de cobertura para as operadoras de planos privados, sendo meramente exemplificativo, e não taxativo, contendo apenas o mínimo de custeio obrigatório.

O Superior Tribunal de Justiça também tem decidido que a ausência do procedimento no rol de procedimentos da ANS não obsta sua prestação exigida pelo beneficiário:

$\begin{array}{llllll}\text { AGRAVO INTERNO NO AGRAVO EM } & \text { RECURSO ESPECIAL. PLANO DE } \\ \text { SAÚDE. TRATAMENTO } & \text { PRESCRITO } & \text { PELO MÉDICO. } & \text { 1. } & \text { DOENÇA } \\ \text { ABRANGIDA } & \text { PELO } & \text { CONTRATO. } & \text { LIMITAÇÃO } & \text { DAS } & \text { SESSÕES }\end{array}$ 
TERAPÊUTICAS. CONDUTA ABUSIVA. INDEVIDA NEGATIVA DE COBERTURA. SÚMULA 83/STJ. 2. COPARTICIPAÇÃO. INVIABILIDADE. REEXAME PROBATÓRIO. SÚMULA 7/STJ. 3. AGRAVO DESPROVIDO.

1. A jurisprudência desta Corte Superior já sedimentou entendimento no sentido de que "não é cabível a negativa de tratamento indicado pelo profissional de saúde como necessário à saúde e à cura de doença efetivamente coberta pelo contrato de plano de saúde". E o "fato de eventual tratamento médico não constar do rol de procedimentos da ANS não significa, per se, que a sua prestação não possa ser exigida pelo segurado, pois, tratando-se de rol exemplificativo, a negativa de cobertura do procedimento médico cuja doença é prevista no contrato firmado implicaria a adoção de interpretação menos favorável ao consumidor" (AgRg no AREsp 708.082/DF, Rel. Ministro João Otávio de Noronha, Terceira Turma, julgado em 16/2/2016, DJe 26/2/2016). 2. No que tange ao pedido de cobrança de coparticipação, a revisão da conclusão quanto à responsabilidade ao custeio integral do tratamento prescrito não prescinde do reexame fático-probatório dos autos, procedimento vedado pelo óbice da Súmula n. 7 do STJ. 3. Agravo interno a que se nega provimento. (AgInt no AREsp 1532303/SP, Rel. Ministro MARCO AURÉLIO BELLIZZE, TERCEIRA TURMA, julgado em 10/02/2020, DJe 13/02/2020)

AGRAVO INTERNO NO AGRAVO EM RECURSO ESPECIAL. AÇÃO DE INDENIZAÇÃO POR DANOS MATERIAIS E MORAIS. PLANO DE SAÚDE. 1. NEGATIVA DE COBERTURA A PROCEDIMENTO CIRÚRGICO SUBSCRITO PELO MÉDICO. EXCLUSÃO CONTRATUAL EXPRESSA E AUSÊNCIA DE PREVISÃO NO ROL DA ANS. CIRCUNSTÂNCIAS QUE NÃO SE MOSTRAM SUFICIENTES A AFASTAR A OBRIGAÇÃO DE COBERTURA DO PROCEDIMENTO PELO PROFISSIONAL DE SAÚDE. $2 . \quad$ ROL EXEMPLIFICATIVO DA ANS E URGÊNCIA EVIDENCIADA. SÚMULAS 7 E 83/STJ. 3. AGRAVO IMPROVIDO. 1. Segundo a jurisprudência desta Corte Superior, ainda que admitida a possibilidade de o contrato de plano de saúde conter cláusulas limitativas dos direitos do consumidor, revela-se abusiva a que exclui o custeio dos meios e materiais necessários ao melhor desempenho do tratamento de doença coberta pelo plano. 1.1. Ademais, é inadmissível a recusa do plano de saúde em cobrir tratamento médico voltado à cura de doença coberta pelo contrato sob o argumento de não constar da lista de procedimentos da ANS, pois este rol é exemplificativo, impondo-se uma interpretação mais favorável ao consumidor. 2. Por derradeiro, que a recusa indevida pela operadora de plano de saúde à cobertura de tratamento médico emergencial ou de urgência constitui dano moral presumido, como na hipótese em apreço, não havendo que se falar em mero inadimplemento contratual. Súmula 83/STJ. 3. Agravo interno a que se nega provimento. (AgInt no AREsp 1553980/MS, Rel. Ministro MARCO AURÉLIO BELLIZZE, TERCEIRA TURMA, julgado em 09/12/2019, DJe 12/12/2019) 
Evidencia-se que a Judicialização da Saúde, traz uma constante preocupação não só aos gestores do Sistema Único de Saúde, bem como dos gestores privados e dos operadores do Direito, especialmente no tocante a necessidade de critérios para pautar as decisões. ${ }^{14}$

Saúde não é mercadoria. Vida não é negócio. Dignidade não é lucro. Direitos conquistados não podem ser retrocedidos sequer instabilizados... Por isso o cuidado jurídico com o tema relativo à saúde é objeto de lei, quer dizer, norma decorrente do devido processo legislativo. No Estado democrático de direito, somente com ampla discussão na sociedade, propiciada pelo processo público e amplo debate, permite que não se transformem em atos de mercancia o que o sistema constitucional vigente acolhe como direito fundamental e imprescindível à existência digna. (ADPF 532 MC/DF. Min. Celso de Mello. Julg. 14/07/2018. DJe: 03/08/2018)

\section{CONCLUSÃO}

O direito à saúde, além de qualificar-se como direito fundamental que assiste a todas as pessoas, representa consequência constitucional indissociável do direito à vida.

O Sistema Único de Saúde foi criado em 1988, pela Constituição da República, porém ainda não representa o ideal desejado. Novas propostas surgiram na década de 90 , dentre elas a Lei Orgânica da Saúde (Lei 8.080/90, que implantou amplamente o Sistema Único de Saúde) e a regulamentação dos Planos de Saúde (Lei n. 9.656/98, que visou equilibrar as relações contratuais, configurando o marco legal da saúde suplementar no Brasil e disciplinou como se daria a forma do ressarcimento ao SUS).

A Saúde Suplementar constitui um sistema provado de serviços de saúde, que se efetiva por meio de convênios ou planos de saúde.

A criação da ANS (Agência Nacional de Saúde) em 2000, configurou um marco importante para o sistema de saúde brasileiro, uma vez que a agência visa buscar sempre instrumentos de eficiência para esse mercado, regulamentando, fiscalizando e controlando o exercício das atividades das operadoras em geral, devendo permitir a competição de forma saudável, em benefício da coletividade.

\footnotetext{
${ }^{14}$ No Estado de Minas Gerais, o Tribunal de Justiça de Minas Gerais efetuou convênio com o NATS - Núcleo de Tecnologia em Saúde do Hospital das Clínicas, que tem sido um instrumento importante, através de notas técnicas que servem de subsídio nas decisões judiciais atinentes à saúde.
} 
No que tange à saúde suplementar, o Estado passou a atuar como regulador dos mercados, por intermédio da agência reguladora - ANS. A própria Constituição Federal, ao dispor sobre a Ordem Econômica, fixou o papel do Estado como agente normativo e regulador das atividades econômicas.

A Saúde Suplementar representa, indubitavelmente, um pilar de sustentação do próprio sistema público de saúde, tendo em vista que o próprio SUS não teria condições de atender a toda população, embora a legislação constitucional vise garantir o acesso universal e igualitário no que tange à saúde.

Desse modo, a Saúde Suplementar tornou-se fundamental para o Estado, que não teria como suportar a incorporação de todos os gastos do setor da saúde no orçamento da União.

O SUS não tem capacidade de absorver o atendimento para todas as pessoas que pagam plano de saúde. Consequentemente, não há como transferir para o SUS todo o atendimento que atualmente é realizado pelo setor privado de saúde.

Verificou-se que a ANS é uma agência reguladora que exerce a autoridade estatal, detendo normas de relações existentes entre as operadoras de planos privados de assistência à saúde e seus respectivos beneficiários, definindo os direitos de ingresso das operadoras no mercado, fiscalizando, determinando suas condutas e aplicando sanções, se for o caso, inclusive se necessário for, retirando as operadoras do mercado.

Indubitavelmente que o Código de Defesa do Consumidor (Lei n. 8.078 de 11/09/90) foi um importante instrumento legal que também contribuiu para a regulamentação do setor de saúde suplementar.

Convém ressaltar o beneficiário de plano de saúde não perde o direito de ser atendido pelo SUS, tendo em vista que o plano de saúde fornece assistência de forma suplementar.

Observou-se que a ANS tem sido por vezes ineficiente. Devido ao enfrentamento da crise econômica das operadoras, as ações de fiscalização da ANS devem ser ampliadas e aperfeiçoadas.

Porém, se o governo pretende controlar a proliferação dos planos de saúde privados, o Sistema Único de Saúde tem que ser reestruturado e bem administrado para oferecer um serviço digno à população brasileira.

Percebeu-se que a ANS tenta aumentar seu poder de controle, basta observar algumas questões atuais advindas de normas regulatórias da ANS, dentre elas, a suspensão temporária 
da comercialização de planos de saúde e a contabilização de negativas de atendimento por parte dos convênios.

Observou-se que o crescimento das demandas judiciais que envolvem o direito à saúde no Brasil, chamado por muitos de fenômeno da Judicialização da Saúde, vem sendo uma constante preocupação dos gestores do Sistema Único de Saúde, bem como dos gestores privados e dos operadores do Direito, especialmente no tocante a necessidade de critérios para pautar as decisões.

O rol de procedimentos da ANS - Agência Nacional de Saúde Suplementar não é exaustivo, pois elenca o mínimo necessário para cobertura pelas operadoras dos planos de saúde.

A atual crise econômica no Brasil, com alto índice de desemprego, bem como a elevação dos custos de planos de saúde tem acarretado a redução do número de pessoas que conseguem ter planos de saúde.

São significativos os desafios na busca constante na melhoria da qualidade de saúde. Contudo, evidenciou-se que cabe à ANS acompanhar de forma constante as incessantes transformações do mercado, para que a população tenha uma saúde digna.

\section{REFERÊNCIAS}

ANS. Agência Nacional de Saúde Suplementar. Cadernos de Informações da Saúde Suplementar, agosto de 2010.

ARAGÃO, A. Agências reguladoras e a evolução do direito administrativo econômico. Rio de Janeiro: Forense, 2002.

ARAGÃO, A. S. Regulação da economia: conceito e características contemporâneas. Revista do Direito da Energia. São Paulo, nº 2, p. 144-201, 2004.

Direito dos serviços públicos. Rio de janeiro: Forense, 2007.

BAHIA, L. Sistema único de saúde. Disponível em <http://www.epsjv.ficruz.br.htm>. Acesso em 11 jan. 2013.

BARBOSA, J. G. B. Agências reguladoras: a metamorfose do estado e da democracia (uma reflexão de Direito Constitucional e Comparado). Revista de Direito Constitucional e Internacional. N. 50. Ano 13. São Paulo : Revista do Tribunais. jan-mar 2005. 
BRASIL. Ministério da Saúde. Agência Nacional de Saúde Suplementar.

Regulação \& Saúde: estrutura, evolução e perspectivas da assistência médica suplementar / Ministério da Saúde, Agência Nacional de Saúde Suplementar. - Rio de Janeiro: ANS, 2002.

CRUZ, J. Direitos do consumidor e regulação dos reajustes de plano de saúde. Disponível em: <http:// www.idec.org.br.htm> Acesso em 22 jun. 2013.

CRUZ, V. Estado e regulação: fundamentos teóricos. In: Regulação e

Agências Reguladoras. Governança e Análise de Impacto Regulatório. Brasília: ANVISA, 2009.

CUÉLLAR, L. As agências reguladoras e seu poder normativo. São Paulo: Dialética, 2002.

ELIAS, P. E. Estado e saúde: os desafios do Brasil contemporâneo. Revista São Paulo em Perspectiva. vol.18 no.3 São Paulo July/Sept. 2004.

FERNANDES NETO, A. J. Plano de Saúde e Direito do Consumidor. Belo Horizonte: Del Rey, 2002.

GAMA, M. V. Um estudo sobre a evolução da indústria de medicina suplementar no Brasil. Dissertação de mestrado. Belo Horizonte: Ibmec, 2006.

Metodologia da pesquisa. Belo Horizonte: PUC Minas Virtual, 2007.

GERSCHMAN, S. Políticas comparadas de saúde suplementar no contexto de sistemas públicos de saúde: União Europeia e Brasil. Revista Ciência e saúde coletiva. vol.13 no.5 Rio de Janeiro, Set./Out. 2008.

GREGORY, M. S. Planos de saúde: a ótica da proteção do consumidor. 2.ed. São Paulo: Revista dos Tribunais, 2010.

LEAL, R. G. A Efetivação do Direito à Saúde - por uma jurisdição Serafim: limites e possibilidades. In Direitos Sociais e Políticas Públicas: desafios contemporâneos. v. 6. Santa Cruz do Sul: Edunisc, 2006.

LIMBERGER, T.; GRISON, L. Políticas públicas de direito à saúde: a necessidade de critérios hermenêuticos para a intervenção judicial. Revista Estudos Jurídicos. ISSN Eletrônico 2175-0491, Santa Cruz do Sul: 2010.

MACERA, A. P.; SAINTIVE, M. B. O mercado de saúde suplementar no Brasil. Brasília: SEAE/MF, 2004.

MAGALHÃES JR., H. M. Regulação assistencial: a busca de novas ferramentas no SUS para enfrentar o desafio de garantir a assistência com equidade. Belo Horizonte: Prefeitura Municipal, 2006. (Pensar BH - política social).

MARTINS. W. Direito à saúde. Belo Horizonte: Fórum, 2008.

Rev. de Direito Sociais e Políticas Públicas | e-ISSN: 2525-9881 | Evento Virtual | v. 6 | n. 1 | 
MATEUS, C. G. Direitos fundamentais sociais e relações privadas: o caso do direito à saúde na Constituição Brasileira de 1988. Porto Alegre: Livraria do Advogado, 2008.

MINISTÉRIO DA SAÚDE (BR). Regulação no setor de saúde: em direção aos seus fundamentos públicos. Brasília: Secretaria da Assistência à Saúde, 2004.

MINISTÉRIO DA SAÚDE (BR). Controle, regulação e avaliação. Brasília: Secretaria da Assistência à Saúde, 2002.

OCKÉ-REIS, C. O.; ANDREAZI, M. F. S de, SILVEIRA, F. G. O mercado de planos de saúde no Brasil: uma criação do Estado ¿ Revista de Economia Contemporânea, Rio de Janeiro, v. 10, n. 1, p. 157-185, jan.-abr. 2006 .

PEREIRA, E. A.; HUSSNE, R. D. Regulação e Padrão Competitivo no Setor de Saúde Suplementar. Revista Brasileira de Risco e Seguro. Rio de Janeiro, v. 6, n. 12, p. 17-36, out. 2010/mar. 2011.

PEREIRA FILHO, L. Iniciativa privada e saúde. Revista Estudos Avançados USP - Dossiê Saúde Pública, v. 13, n. 35, 1999.

RAMALHO, P. I. S. Regulação e Agências Reguladoras: reforma regulatória da década de 1990 e desenho institucional das agências no Brasil. In: Regulação e Agências Reguladoras. Governança e Análise de Impacto Regulatório. Brasília - ANVISA, 2009.

REIS, C. O. O. A reforma institucional do mercado de planos de saúde: uma proposta para criação de benchmarks. Rio de Janeiro: Ipea, 2005.

RIANI, M. K. Planos de saúde: a harmonização dos interesses na relação de consumo. Dissertação apresentada ao curso de mestrado em Direito empresarial da Faculdade de Direito Milton Campos. Nova Lima, 2010.

SANTOS, F. P.; MERHY, E. E. Public regulation of the health care system in Brazil - a review. Interface -Comunic., Saúde, Educ., v.10, n.19, p.25-41, jan/jun 2006.

SANTOS, F. P.; Malta, CARVALHO, D.; MERHY, E. E. A regulação na saúde suplementar: uma análise dos principais resultados alcançados. In: A saúde suplementar e o modelo assistencial brasileiro: situação atual e perspectivas. Ciência \& Saúde Coletiva, vol. 13 número 5. Abrasco. set/out 2008.

SANTOS, L.A. dos. A saúde suplementar no Brasil: regulação capturada e direitos em risco. n. 175. Publicado em 20-08-2018. Disponível em www.teoriaedebate.org.br Acesso em 26 de fev. 2020.

SILVA, J,. S. L da. Planos de saúde e boa-fé objetiva: uma abordagem crítica sobre os reajustes abusivos. Salvador: JusPodivm, 2008. 
SILVA, R. V. Ineficiência da ANS impulsiona reajustes abusivos. Publicado em 07 de ago. 2013. Acesso em www.saudeweb.com.br Acesso em 18 ago. 2013.

SOUSA, S. L. S. e. Direito à saúde e políticas públicas. Belo Horizonte: Del Rey, 2015.

SUNDFELD, C. A. Fundamentos do Direito Público. São Paulo: Malheiros, 2011.

Agências reguladoras de serviço público: 10 anos de Constituição - uma análise. São Paulo: Celso Bastos, 1998.

TESSLER, M. I. B. O direito à saúde: a saúde como direito e como dever na Constituição Federal de 1988. Revista do Tribunal Federal da $4^{\text {a }}$ Região, Porto Alegre, nº 40, p.80-81, 2001.

VIEIRA, W. M. Direito à saúde: compêndio. Belo Horizonte: Fórum, 2008. 